\title{
An economic theory of cigarette addiction
}

\author{
Steven M. Suranovic ${ }^{\mathrm{a}, *}$, Robert S. Goldfarb ${ }^{\mathrm{a}}$, \\ Thomas C. Leonard ${ }^{\mathrm{b}}$ \\ a Department of Economics, The George Washington University, 2201 G St. N.W., Washington, DC \\ 20052, USA \\ ${ }^{\mathrm{b}}$ Department of Economics, Princeton University, Princeton, USA
}

Received 1 July 1996; revised 1 March 1998; accepted 30 April 1998

\begin{abstract}
In this paper we present a model in which individuals act in their own best interest, to explain many behaviors associated with cigarette addiction. There are two key features of the model. First, there is an explicit representation of the withdrawal effects experienced when smokers attempt to quit smoking. Second, there is explicit recognition that the negative effects of smoking generally appear late in an individual's life. Among the things we use the model to explain are: (1) how individuals can become trapped in their decision to smoke; (2) the conditions under which cold-turkey quitting and gradual quitting may occur; and (3) a reason for the existence of quit-smoking treatments. (C) 1999 Elsevier Science B.V. All rights reserved.
\end{abstract}

JEL classification: I10; D11; D91

Keywords: Addiction; Smoking; Intertemporal choice; Habitual consumption

\section{Introduction}

Economists model human behavior by assuming that individuals act in their own best interest. We describe agents as maximizing utility when they make rational choices consistent with their preferences, given their beliefs. Yet classes of widespread behaviors seem to prima facie contradict this assumption. Millions

\footnotetext{
* Corresponding author. Tel.: +1-202-994-6150; Fax: +1-202-994-6147; E-mail: smsuran@gwu.edu
} 
of consumers smoke cigarettes, overindulge in food and drink, pay taxes too soon, procrastinate, and save or exercise too little. To the extent that these choices are not what people want, they present a puzzle for standard economic theory.

An economic modeling answer to this puzzle is found in rational addiction models, which build on earlier analyses in which the individual's past consumption patterns affect present choices (see, for example, Pollak, 1970, and Stigler and Becker, 1977). In the addiction analysis of Becker and Murphy (1988) they assume that agents choose an overlife consumption path to maximize expected utility and show that addiction is consistent with rational behavior.

Another theory of addiction is the 'multiple selves' approach that embodies competing preferences. In these models a smoker would have one 'self' who wants to smoke competing against her non-smoker 'other self'. (examples of such approaches, not necessarily focusing on addiction, include Schelling, 1984 and Thaler and Shefrin, 1981).

In the medical literature it is sometimes suggested that addictions are 'diseases' arising out of biological predispositions. This approach places the choice about using addictive substances beyond the individual's control. ${ }^{1}$ Finally, psychologists sometimes describe addictions using 'primrose path' theories. In this view individuals are lured into addiction either because the latent costs are initially hidden or because of a faulty reasoning process. ${ }^{2}$

In this paper we focus on one common addictive behavior-cigarette smoking. We present a model of cigarette consumption in which self-interested individuals choose to become addicted. The model incorporates many of the same elements from the Becker-Murphy rational addiction analysis. However, we reinterpret or re-characterize some of the effects.

For example, the Becker-Murphy analysis suggests that potential addiction arises whenever consumption of a good displays adjacent complementarity. This implies that someone is addicted to a good only when past consumption of the good raises the marginal utility of present consumption. Becker-Murphy note further that adjacent complementarity is closely related to the principle of rein-

\footnotetext{
${ }^{1}$ Thombs (1994) notes that, according to the disease view, excessive consumption of alcohol or drugs is the result of an "underlying disease process...thought to cause compulsive use; in other words, the high rate and volume of use are merely the manifest symptoms of an illness. The exact nature of the illness is not fully understood at this point, but many proponents of the disease model believe that it has genetic origins... If the disease... is not present, then dependencies cannot develop, no matter how much of the substance is consumed. The 'addiction as a disease' model maintains that the alcoholic and addict are victims of an illness". (pp. 3-4). Thombs contrasts the moral and disease models of addiction to a view of 'addiction as maladaptive behavior'. For additional discussion of the disease model, see the articles in Peele (1988).

${ }^{2}$ This characterization of approaches to modeling addiction is from Herrnstein and Prelec (1992). Viscusi (1992), whose work focuses on individuals' risk perceptions about smoking, specifies three modeling approaches: the fully rational smoker; the stylized smoker who is ignorant of the hazard of smoking; and the smoker with cognitive limitations.
} 
forcement, which means that greater current consumption raises future consumption, and that reinforcement is a feature of many addictive goods. However, an additional implication of adjacent complementarity is a negative utility effect whenever an individual with a past consumption stock attempts to curtail present consumption. In our model we incorporate this negative utility effect explicitly and interpret it as a quitting or withdrawal cost. The presence of quitting costs is shown to be the critical element in making a good addictive. ${ }^{3}$

The assumption of quitting costs is consistent with the medical literature which indicates that smoking cessation imposes recognizable negative utility effects. Harris (1993), a practising physician and a health economist, provides a useful summary of the medical evidence of withdrawal effects in the book Deadly Choices. Harris argues that quitting smoking requires management of 'nicotine withdrawal', a 'well-defined condition'. Those trying to quit 'become impatient or frustrated or anxious or nervous or restless.... They go through an experience that is nearly universal among millions of people every time they try to quit. They have the well-documented symptom of a recognized medical syndrome". (Harris, pp. 163-164) Harris argues that, without some form of nicotine replacement, "virtually every regular smoker who abstains from cigarettes will go through his or her own version of nicotine withdrawal" (p. 165) In a broader sense, withdrawal occurs even if there is nicotine replacement, reflecting both deprivation (relative to actual smoking) in the dose and speed of delivery of nicotine, and behavioral/psychological deprivation. ${ }^{4}$

High relapse rates provide evidence that smokers who want to quit, have extreme difficulty doing so. Harris indicates that, of those who begin an attempt to quit smoking in week $0,46 \%$ are still abstaining after 1 week, $25 \%$ after 4 weeks, and only $8 \%$ after 1 yr. Harris asserts that, "(w)hen it comes down to it, what caused my patients' symptoms and what precipitated their relapse was their inability to manage their nicotine withdrawal symptoms". 5 Prochaska et al. (1992), publishing in the psychology literature, note that "relapse is the rule rather than the exception with addictions". (p. 1104). They cite an earlier study indicating that people who successfully stop smoking "make an average of three to four ... attempts" before they succeed (p. 1104).

\footnotetext{
${ }^{3}$ Note that a negative utility effect from reductions in consumption is present in both models. What differs is our interpretation that the effect is a withdrawal cost rather than a reinforcement effect. This interpretation leads us to model adjustment costs asymmetrically. In other words, in our model adjustment costs arise if a smoker reduces consumption, but not if the smoker raises consumption. We believe this makes sense since we know of no evidence that temporarily overindulging in smoking would cause any immediate adjustment cost.

${ }^{4}$ Other analysts have also noted the potential significance of quitting costs. For example, Viscusi (1992) (p. 11) notes that " $(\mathrm{t})$ here are clearly costs of change associated with smoking behavior. The fact that quitting smoking is even an issue, implies the presence of some adjustment costs".

${ }^{5}$ These relapse rates are based on Harris's calculations, using reports on 7510 current and former smokers polled in the 1978-1980 National Health Interview Surveys. See Harris, pp. 167-68.
} 
Perhaps the most essential aspect of addiction is the habitual behavior it generates. However, repetitive usage of a good is not sufficient to call consumption of that good an addiction. For example, regular consumption of a good such as breakfast cereal is rarely described as addictive even though it is consumed habitually. Instead, addiction requires that someone would like to either cease or reduce habitual consumption but is unable to do so. In this paper we show that explicit recognition of quitting costs can explain why people seemingly wish to do one thing but choose another.

Another feature in the Becker-Murphy model is the direct effect that the past stock of cigarette consumption has on present utility. If the potentially addictive goods are harmful, as with cigarettes, then current consumption will have a detrimental effect upon future utility and earnings. Becker-Murphy note that harmful goods imply a form of tolerance (another feature of many addictions) since higher past consumption lowers the present utility for a fixed consumption level. For cigarettes this negative effect also clearly relates to the detrimental health consequences that are likely to arise from consumption. Another feature of cigarette consumption, not explicitly incorporated into the Becker-Murphy framework, is that many of the detrimental effects, especially the development of various cancers, will occur in the distant future. In fact, for purposes of simplifying the exposition of our model, we will make the extreme assumption that the entire detrimental effect of smoking comes 'at the end of life'. Subsequently, we will show that, with some modifications, our results hold even under the more realistic assumption that smoking affects the probability of death at every age.

In order to enhance the intuition of our results we make some simplifying assumptions about the nature of the choice problem faced by the individual. Whereas Becker-Murphy assume that the individual chooses a lifetime consumption path to maximize the present value of lifetime utility, we shall assume that the individual chooses only how much to consume today. While we do allow the individual to take account of the first-order effects of today's decision on future utility, we do not allow him to make the superhuman calculations that are necessary to form a fully consistent lifetime consumption path. As such our agent may be thought of as being 'boundedly rational' in the sense of Herbert Simon (1978). ${ }^{6}$

\footnotetext{
${ }^{6}$ Yaari (1978) usefully illuminates this issue by discussing a model in which a fur trader periodically exchanges whiskey with a trapper. The price of the whiskey is continually raised by the fur trader as the trapper becomes 'addicted'. Yaari contends that if the trapper were fully rational with perfect information, he would have taken account of the alcohol's addictive effect in his early trades and thus could have changed his consumption path to increase the present value of his lifetime utility. The solution of this problem, however, requires a complicated backward induction procedure that requires planning for all future decisions. One way to justify bounded rationality within our model is to assume that the backwards induction procedure is too costly to make it worth pursuing. In other words the evaluation costs are prohibitive. Furthermore allowing the future health cost evaluation while not allowing the backwards induction procedure is reasonable since there is an abundance of public information about the long term effects of smoking.
} 
In addition to the improvement in intuition, our model can explain behavior that, seemingly, cannot be explained using any other single approach. For example, this model can clearly show why utility maximizing individuals may be unhappy about being smokers, express a sincere desire to quit, yet find themselves unable to do so. ${ }^{7}$ We can also explain why merely growing older is sufficient to induce some smokers to quit. In addition, the model can generate cold-turkey quitting without relying on an exogenous shock or stressful event as in BeckerMurphy. The motivation to quit is based instead on changes in the smoker's perspective as he grows older. The model also shows that some individuals may quit smoking by gradually reducing consumption over time, a result not explicitly derived by Becker-Murphy. Finally, this model provides a simple explanation for 'quit-smoking' treatments like Smokenders and nicorette gum used by smokers attempting to quit. In the rational addiction models it is not clear why smokers would ever seek out such treatments.

We begin in Section 2 with a complete description of the model. In Section 3 we use the model to explain the decision to begin smoking and to explain habitual usage. In Section 4 we explain how both cold-turkey quitting and gradual quitting may arise. In Section 5 we summarize the results of the alternative model developed in the appendix. In Section 6 we consider the responsiveness of cigarette demand to exogenous shocks such as price changes. In Section 7 we apply the model to explain behavior modification treatments and the potential effects of advertising. Finally we conclude in Section 8 with a summary and suggestions for further research.

\section{The model}

We assume that the effects of smoking at age $A$ can be decomposed into three additively separable components, current benefits $\left(B_{A}\right)$, future losses $\left(L_{A}\right)$, and an adjustment $\operatorname{cost}\left(C_{A}\right)$.

\subsection{Current benefits}

Current benefits represent utility derived in the period in which the smoking occurs. It could include the pleasurable effects of nicotine, the satisfaction of being accepted by a peer group or the satisfaction of rebelling against parents. We

\footnotetext{
${ }^{7}$ Our model can clearly depict why the choice to smoke need not be associated with a so-called 'happy addict'. The inability to generate 'unhappy addicts' was one of the criticisms of Winston (1980) of the rational addiction framework. Becker-Murphy note that addictions can sometimes arise out of stressful life events, thereby producing unhappy addicts; our model generates unhappy addicts without assuming stressful life events or other exogenous devices.
} 
assume that utility (or benefits) from smoking at age $A,\left(B_{A}\right)$, increases at a decreasing rate as present consumption of cigarettes $(s)$ rises:

$$
B_{A}=B_{A}(s) \quad B_{A} \geq 0, B_{A}^{\prime}>0, B_{A}^{\prime \prime}<0, \forall s \geq 0 .
$$

Note that current costs of smoking such as social disapprobation could easily be included as a negative entry in the current benefit function in which case benefits are reinterpreted as net current benefits.

\subsection{Future losses}

Current disutility from future losses arises because of the expected detrimental health effects that can be caused by current smoking. The Centers for Disease Control and Prevention recently reported their calculation that every cigarette reduces one's life by seven minutes. ${ }^{8}$ We can model this by assuming that individuals expect to live until some fixed age defined by their life expectancy. We then assume that every cigarette consumed reduces one's life expectancy. ${ }^{9}$ Individuals evaluate future losses by calculating the present discounted value of expected reductions in length of life. ${ }^{10}$

Assume the individual is currently $A$ years old. Let $T(A)$ represent a nonsmoker's life expectancy at age $A$ (i.e. the number of years remaining). Data for average life expectancies for the entire US population in 1989 indicate that life expectancy declines almost linearly until about age 50 when it begins to decrease at a decreasing rate. For simplicity we will assume $T(A)$ is linear so that $T^{\prime}(A)<0$ and $T^{\prime \prime}(A)=0$.

Assuming every cigarette smoked reduces life expectancy by a fixed amount $\alpha$, a smoker's life expectancy at age $A$ can be represented as $T(A)-\alpha S_{A}$, where

\footnotetext{
${ }^{8}$ See NY Times editorial, Sept. 1, 1993, p. 18.

${ }^{9}$ This assumption is consistent with empirical findings that smokers expect smoking to shorten their lives. For example, Hamermesh and Hamermesh (1983) showed that white male smokers estimate their longevity as four years less than that of nonsmokers. Recent analyses suggest that the actual life expectancy loss may be closer to seven years than to four. Note that the $7 \mathrm{~min}$ per cigarette figure seems consistent with a $7 \mathrm{yr}$ loss of life. This is based on multiplying 7 min times $30+$ cigarettes a day over $50+\mathrm{yr}$, the average lifespan of a beginning smoker. The 4 yr estimate by smokers vs. the view that the true actuarial effect is $7 \mathrm{yr}$ is consistent with the study by Schoenbaum (1997) showing that smokers consistently underestimate the life expectancy consequences of smoking.

${ }^{10}$ An alternative modeling strategy would be to assume that each cigarette smoked raises the probability of dying at all future ages. Under this assumption, one's current perception of future losses will tend to rise at younger ages and may fall at higher ages. We pursue this alternative modeling strategy in an appendix; how this alternative changes results is discussed in the text below, after our explication of the text model. Smoking may also result in poorer future health due to emphysema or heart disease and even losses of future income. In one sense this is similar to the appendix model in that a reduction in quality of life would reduce expected utility over a span of years. However, quality of life or income effects may be more likely to be 'lumpy' (e.g., arising only in the last ten years of life with a variation in degree) rather than to arise gradually and systematically as the appendix model assumes.
} 
$S_{A}=\int_{t=0}^{A} s_{t} \mathrm{~d} t$ is the total stock of past cigarette consumption. The present value of a smoker's expected future utility stream $(V)$ at age $A$ can now be written as,

$$
V(A, s)=\int_{t=A}^{T(A)+A-\alpha\left(S_{A}+s\right)} e^{-r(t-A)} W_{t} \mathrm{~d} t
$$

where $r$ is the fixed discount rate, $e^{-r(t-A)}$ is the discount factor at time $t$, and $W_{t}$ is the individual's expected utility in period $t{ }^{11}$ Recall that $s$ represents this period's cigarette consumption. Thus, $\alpha s$ in the upper limit is the additional lost life caused by today's smoking while $\alpha S_{\mathrm{A}}$ is the lost life caused by all previous smoking.

For an individual at age $A$, the present value of the expected future losses resulting from this period's smoking is given as,

$$
L_{A}(s)=V(A, 0)-V(A, s)=\int_{T(A)+A-\alpha\left(S_{A}+s\right)}^{T(A)+A-\alpha S_{A}} e^{-r(t-A)} W_{t} \mathrm{~d} t .
$$

Note that utility is evaluated only over the lost moments of one's life $(\alpha s)$ that result from smoking today. The first and second derivatives of the future loss function $L_{A}$ with respect to $s$ are:

$$
\begin{aligned}
& L_{A}^{\prime}=\alpha e^{-r\left(T(A)-\alpha\left(S_{A}+s\right)\right)} W_{T(A)+A-\alpha\left(S_{A}+s\right)} \geq 0 \\
& L_{A}^{\prime \prime}=(\alpha)^{2} e^{-r\left(T(A)-\alpha\left(S_{A}+s\right)\right)} W_{T(A)+A-\alpha\left(S_{A}+s\right)} \geq 0 .
\end{aligned}
$$

Future losses increase with smoking since each cigarette eliminates expected benefits in the final moments of life. Losses rise at an increasing rate because each cigarette draws the terminal date closer resulting in a higher discount factor being applied to the final minutes of life.

\subsection{Adjustment costs}

An adjustment cost $\left(C_{A}\right)$ represents the discomforts that arise when the consumption of cigarettes is reduced or eliminated. These effects are well-documented as withdrawal effects of nicotine addiction and may include anything from a loss of concentration to extreme irritability.

The adjustment cost will likely depend upon the amount, recency and general pattern of past consumption as well as the degree of the current consumption cutback. For example, as the stock of past consumption of cigarettes rises, the cost of quitting probably rises, though perhaps at a decreasing rate. There may be an asymptotic limit to the amount of quitting cost that would ever be realized (a two-pack a day smoker may suffer as much as a three-pack a day smoker when quitting 'cold turkey'). How recently the past consumption of the addictive good occurred will also likely affect the size of the quitting cost. Zero consumption of

\footnotetext{
${ }^{11}$ We will assume that $T(A)-\alpha\left(S_{A}+s\right)>0$.
} 
cigarettes on a day following a month of chain-smoking is likely to be more painful than zero consumption one year from one's last cigarette. The quitting cost may also be higher the more 'patterned' is one's past consumption of the good. For example, the cost of quitting smoking may be higher for individuals who always had smoked a cigarette immediately after every meal. Finally, a quitting cost need not only arise when consumption drops to zero. A mere reduction of consumption of an addictive substance will probably have deleterious effects.

We incorporate many of these effects in a general specification by assuming that adjustment cost at age $A, C_{A}(s)$, is a function of one's past smoking history, defined as $H_{A}=\left\{s_{t}\right\} \forall t \in[0, A]$ and of current consumption, $s$.

$$
\begin{aligned}
& C_{A}=C\left(s ; H_{A}\right) \quad \forall s \in\left[0, s_{\mathrm{h}}\right] \\
& C_{A}=0 \quad \forall s \geq s_{h} .
\end{aligned}
$$

We assume consumption at any level equal or greater than one's habitual consumption level $\left(s_{\mathrm{h}}\right)$ imposes no withdrawal cost. ${ }^{12}$ As consumption is reduced below one's habitual level, cost rises. The greatest cost would occur with an immediate reduction to zero (i.e. with cold-turkey quitting). ${ }^{13} \mathrm{We}$ will assume $C_{A}^{\prime}<0$, that is, adjustment costs fall as $s$ approaches the habitual level. However, there is no a priori reason for a particular sign to $C_{A}^{\prime \prime}$. Thus we will consider both increasing and decreasing cost functions in the analysis below.

\subsection{The individual's problem}

We assume that an individual at age $A$ chooses a quantity of current cigarette consumption and a quantity of a composite good $y$ subject to a budget constraint so as to maximize the present value of the previously defined current and expected net benefits. The composite good generates utility only in the current period and has a utility function that is additively separable from cigarette utility. We define $U_{A}(s)=B_{A}(s)-L_{A}(s)-C_{A}(s)$. The individual's problem then is,

$$
\begin{aligned}
& \underset{s, y}{\operatorname{MAX}} W_{A}=U_{A}(s)+\Gamma(y) \\
& \text { s.t. } p_{s} s+p_{y} y=I_{A}
\end{aligned}
$$

where $\Gamma$ is the utility function for the composite good $y . W_{A}$ is the sum of the current utility effects from consumption of cigarettes and the composite good at

\footnotetext{
${ }^{12}$ The habitual smoking level, $s_{\mathrm{h}}$, is the individual's average daily consumption rate, below which withdrawal costs arise. How this habitual consumption level can arise is explained later.

${ }^{13}$ This assumption need not necessarily be correct. The other possibility is that, by smoking only a few cigarettes a day, smokers keep nicotine in their systems and effectively 'tease' their bodies into wanting more. Complete quitting probably rids the body of nicotine in a matter of weeks.
} 
age $A . p_{s}$ and $p_{y}$ are the prices of cigarettes and the composite good respectively, and $I_{A}$ is income at age $A$. The first order Kuhn-Tucker conditions are,

$$
\begin{aligned}
& \Gamma^{\prime}-\mu p_{y} \geq 0 \\
& U_{A}^{\prime}-\mu p_{s} \geq 0
\end{aligned}
$$

where $\mu$ in the marginal utility of income. The second-order sufficient conditions for a maximum are,

$$
U_{A}^{\prime \prime}<0 \text { and } \Gamma^{\prime \prime}<0 \text {. }
$$

\section{Early stages of addiction}

\subsection{Starting to smoke}

For a young person whose friends do not smoke and who has little interest in, or understanding of, the physical effects of nicotine, the current benefits of smoking will be non-existent or unknown, so there appears to be no incentive to begin smoking. To generate such an incentive, consider the teenager whose friends begin lighting up cigarettes in a secluded location and encourage participation. Suddenly current benefits exist that did not exist previously. Alternatively, exposure to advertisements and to other smokers may raise a young person's interest in experimentation with a previously forbidden commodity. In either case, events such as these can be represented in our model as an upward shift in one's current benefit function (i.e. an exogenous shock in a shift parameter in $B_{A}$ ). ${ }^{14}$ Other benefits of smoking, like the effects of nicotine, may not become known until cigarettes are experienced a few times. Once a teenager knows her benefit function, regular cigarette consumption may begin.

Since the teenager's smoking history is limited at this early stage, we assume the current adjustment costs are negligible. Future losses are distant and, due to discounting, have only a small effect on present welfare. Nevertheless we assume the teenager takes full account of these expected losses. ${ }^{15}$ In Fig. 1 we plot a benefit function $\left(B_{A}\right)$, a future loss function $\left(L_{A}\right)$ and the difference between the two $\left(U_{A}\right)$. The optimal consumption of cigarettes, $s_{0}$, is found by equating the

\footnotetext{
${ }^{14}$ Note that the requirement of an exogenous shock to explain the decision to start smoking is the same assumption used by Becker-Murphy.

${ }^{15}$ The teenager may also be aware that smoking today will make it harder to quit in the future. Certainly teenagers are informed that smoking is addictive. Nevertheless, even if this effect is anticipated, smoking may begin for a couple of reasons. First, if a teenager anticipates a quit date sufficiently far in the future then the discounted future quitting costs would be too small to affect his current decision. Second, if quitting is an 'experience bad' the teenager may underestimate the future quitting cost such that it does not affect his decision to start smoking. This second point is consistent with survey data indicating that large majorities of beginning smokers say they will definitely not be smoking in five years, yet large majorities of them are still smoking five years later.
} 


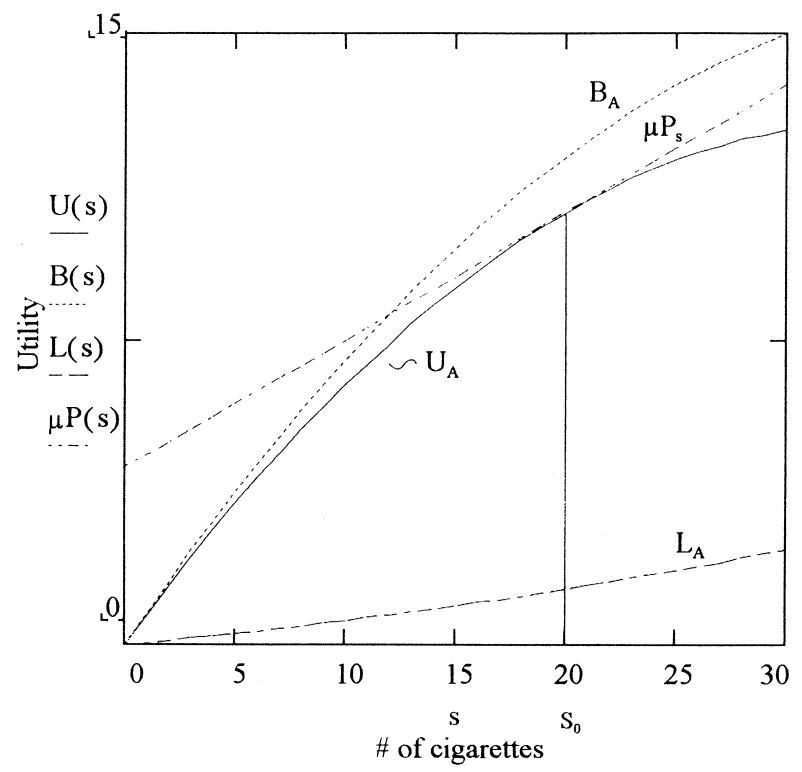

Fig. 1.

marginal utility from smoking $\left(U_{A}^{\prime}\right)$ to the marginal cost $\left(\mu p_{s}\right)$. According to the graph the optimum occurs at the level of 20 cigarettes. ${ }^{16}$

\subsection{Becoming addicted to cigarettes}

We assume that as an individual establishes a consumption history, withdrawal effects or quitting costs develop. In Fig. 2 we introduce a simple adjustment cost function, $C_{A}$, which rises linearly as consumption is reduced below one's average usage level $s_{\mathrm{h}}$. Since the cost function is kinked at $s_{\mathrm{h}}$ (because there are no quitting costs above $s_{\mathrm{h}}$ ), total utility from smoking, $U_{A}=B_{A}-L_{A}-C_{A}$, is kinked at $s_{\mathrm{h}}$ as well. The optimal consumption level will remain at $s_{\mathrm{h}}$ since $U_{A}^{\prime}>\mu p_{s}$ for $s<s_{\mathrm{h}}$, (i.e. when evaluated from the left of the kink) while $U_{A}^{\prime}=\mu p_{s}$ at $s_{\mathrm{h}}$ evaluated from the right.

The development of adjustment costs in response to regular cigarette usage is sufficient to explain why smoking is habit-forming. The presence of adjustment costs will make it difficult to reduce cigarette consumption after any exogenous shock such as a price increase. If adjustment costs were not present, any increase in the price of cigarettes would raise the individual's marginal cost and induce a reduction in consumption. However, when adjustment costs do exist, due to the

\footnotetext{
${ }^{16}$ The plots in the figures were drawn using MathCad. The functional forms were chosen to generate the same shapes assumed in the general specification of the model. Twenty units was chosen merely as a convenient reference point.
} 


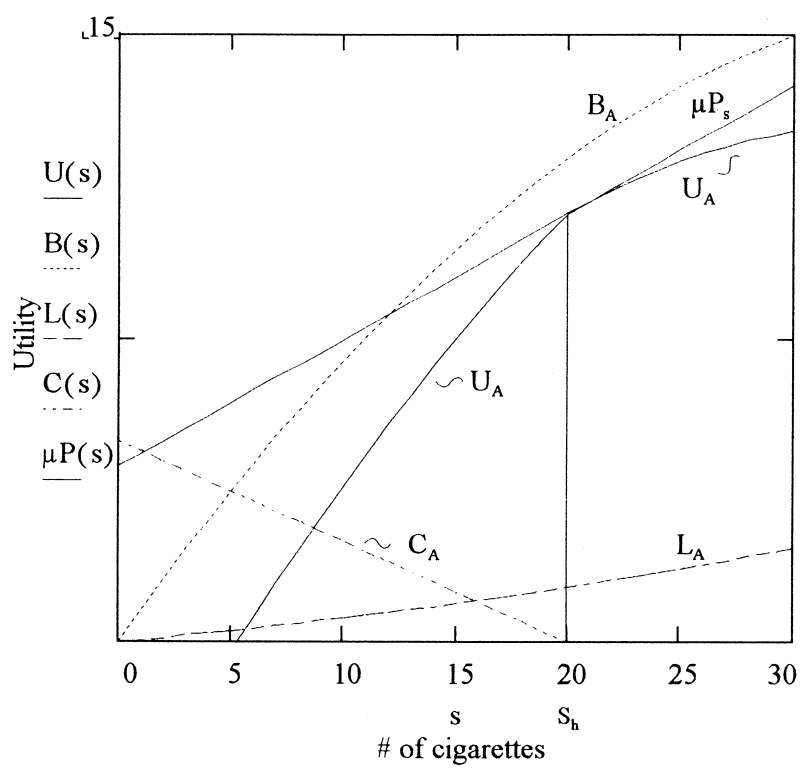

Fig. 2.

kink at $s_{\mathrm{h}}, U_{A}^{\prime}>\mu p_{s}$. Thus, a small increase in the price of cigarettes will no longer reduce consumption. This suggests that a small consumption tax on cigarettes may have no effect on a smoker's consumption level. In this way a regular, habitual smoking level, like $s_{\mathrm{h}}$, may arise which is insensitive to small exogenous shocks in the parameters.

Also notice that once quitting costs are present, low levels of cigarette consumption (less than 5 in Fig. 2) generate negative utility. This is consistent with a common belief among addiction experts that addicts must have a certain minimum number of cigarettes to satisfy their addiction. Our model would suggest that consumption of less than that minimum is actually painful for the smoker.

\section{Breaking the addiction to cigarettes}

As a cigarette smoker becomes older, the future loss function, $L_{A}$, which is a function of age, begins to change. To show how it changes we differentiate Eq. (3) with respect to age $(A)$ to get,

$$
\begin{aligned}
\frac{\partial L_{A}}{\partial A}= & \left(T^{\prime}(A)+1\right) W_{T(A)+A-\alpha S_{A}} e^{-r\left(T(A)-\alpha S_{A}\right)}-\left(T^{\prime}(A)+1\right) \\
& \times W_{T(A)+A-\alpha\left(S_{A}+s\right)} e^{-r\left(T(A)-\alpha\left(S_{A}+s\right)\right)} \\
& +\int_{T(A)+A-\alpha\left(S_{A}+s\right)}^{T(A)+A-\alpha S_{A}} r e^{-r(t-A)} W_{t} \mathrm{~d} t \geq 0 .
\end{aligned}
$$


Future losses rise as one gets older because the discount factor used to weight end-of-life utility rises as aging draws one closer to the terminal date. The effect of the rising loss function on the individual's consumption decision will depend on the shape of the individual's adjustment cost function. We shall consider the case of a long-time smoker and assume that the adjustment cost function has reached an asymptotic limit. This would imply, for example, that the withdrawal effects experienced by a 10-yr smoker are the same as if he were an 11-yr smoker. We shall consider three cases below. First we assume that adjustment costs change at an increasing rate, $C_{A}^{\prime \prime}>0$, as one reduces consumption below the habitual level. In case two we assume adjustment costs change at a decreasing rate, $C_{A}^{\prime \prime}<0$. In case three we assume adjustment costs change at an increasing rate for consumption reductions near the habitual level but at a decreasing rate for consumption reductions near zero.

\subsection{Case 1}

An adjustment cost that rises at an increasing rate, $C_{A}^{\prime \prime}>0$, implies that small reductions in cigarette consumption below an habitual level will have relatively small withdrawal effects. We will refer to this case as a weak addiction since it doesn't hurt much to cut back consumption slightly. However, when consumption is reduced further, adjustment costs eventually rise rapidly. This function is graphed in Fig. 3. Assume that at age $A 1$ the smoker perceives future losses to be $L_{A 1}$ and that overall utility effects are shown by the function $U_{A 1}$ (note that $U_{A 1}=B_{A 1}-C_{A}-L_{A 1}$ and the benefit function $B_{A 1}$ is not drawn). The optimum at age $A 1$ occurs at the habitual level $s_{\mathrm{h}}$.

Next suppose that by age $A 2(>A 1)$, the future loss function has shifted to $L_{A 2}$. Assuming that the adjustment and benefit functions remain unchanged, total utility shifts to $U_{A 2}$. From Eq. (10) we can see that at each consumption level the slope of $U_{A}$ is reduced as age rises from $A 1$ to age $A 2$. Assuming that the price of cigarettes remains unchanged, consumption will fall to $s_{2}$. As one grows even older the future loss function will continue to shift up, gradually reducing cigarette consumption. ${ }^{17}$ Eventually $U_{A}^{\prime}(0)<\mu p_{s}$ and the optimal consumption becomes zero. Thus with a 'weak' addiction a smoker will quit smoking gradually over time.

Notice that with the loss function $L_{A 2}$, total utility derived from smoking at the optimal consumption level is negative. This means that the net effects of smoking

\footnotetext{
${ }^{17}$ As consumption falls, the habitual consumption level would also likely fall implying a shift of the adjustment cost function. Since these costs change at an increasing rate, however, the slope of $W_{A}$ will be dominated at $s_{\mathrm{h}}$ by the benefit and loss functions so the gradual consumption reduction effect will remain.
} 


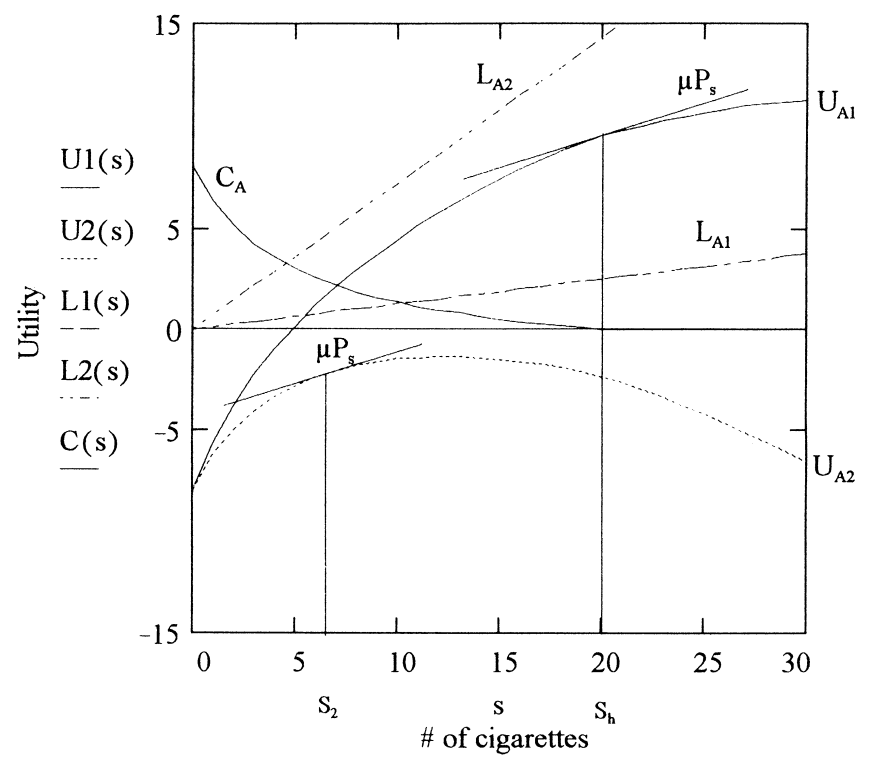

Fig. 3.

are perceived as painful by the smoker since the present value of the future losses weigh so heavily that they exceed the current benefits. The smoker in this situation may wish to be like one of his non-smoking friends who get zero utility from smoking. However, he cannot simply choose to be a non-smoker and attain zero utility since he has a smoking history which induces adjustment costs. His desire to be like his non-smoker friends is like wishing he had a higher income; certainly he would be better-off with more income, but the option is simply not in his choice set. For him, smoking is bad, but quitting is worse so he will continue to smoke while simultaneously wishing he didn't. In this case the smoker can rightfully be called an 'unhappy addict'.

What makes this situation especially interesting is that the smoker has become trapped through his own choices and is unable to extricate himself. ${ }^{18} \mathrm{Had}$ he made different consumption choices in the past he could have higher utility today, thus this individual may reasonably regret his past decisions. But to achieve higher utility today, his past choices would have had to be suboptimal from his past perspective.

Orphanides and Zervos (1995) use an adaptation of the B-M model to also show that smokers may come to regret their past choices. They assume that

\footnotetext{
${ }^{18}$ For examples of other situations where individuals become trapped in undesirable situations see Cross and Guyer (1980).
} 
potential smokers either are an 'addictive type' or they are not. If a non-addictive type smokes it will cause no detrimental future consequences. However, if an addictive type smokes it will cause detrimental future consequences. Thus if an individual decides to smoke hoping he is a non-addictive type, but learns later that he is an addictive type then he will regret his previous decision. In this model regret arises entirely out of the resolution of uncertainty. In contrast, regret in our model does not involve uncertainty; the individual is assumed to have the same information available at all times. Instead regret arises because of the change in perspective that arises because the smoker is assumed to make choices only for the present moment.

\subsection{Case 2}

Adjustment costs that rise at a decreasing rate, $C_{A}^{\prime \prime}<0$, imply that small reductions in cigarette consumption below an habitual level will have relatively large withdrawal effects. This we will refer to as a strong addiction since it is very painful to cut back consumption, even a little. As consumption is reduced further, the adjustment costs rise more slowly. This function is graphed in Fig. 4. Assume that at age $A 1$ the smoker's overall utility effects are shown by the function $U_{A 1}$. (Note: we have not graphed $B_{A 1}$ or $L_{A 1}$.) The optimum occurs at point $G$ with

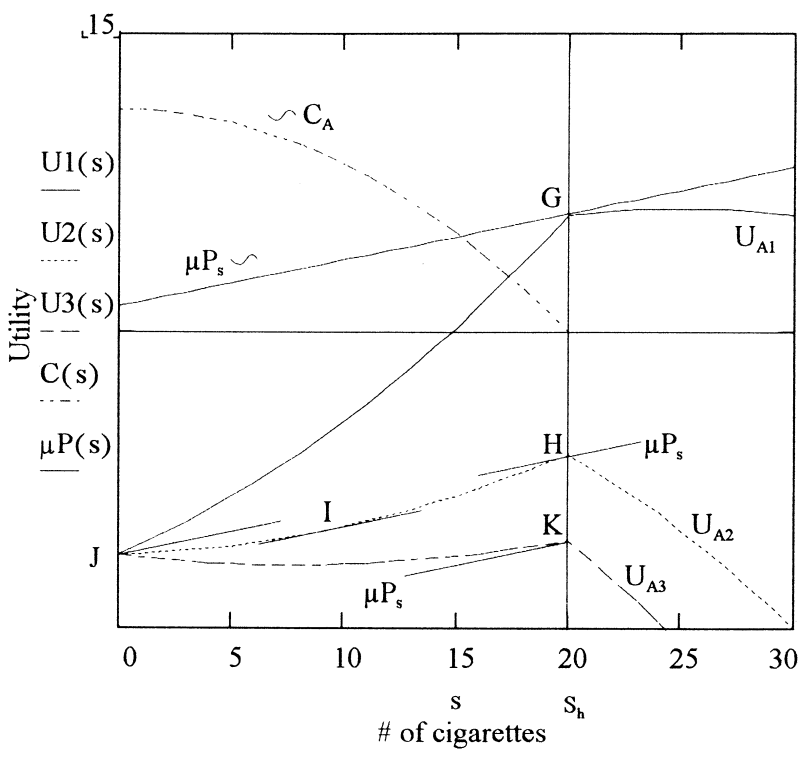

Fig. 4. 
consumption level $s_{\mathrm{h}}$. Just as in case one, as one grows older the utility function shifts down while the slope of $U_{A}$ falls at all $s$. Eventually the smoker will face the utility curve $U_{A 2}$.

Along $U_{A 2}$ three points satisfy the first-order conditions in Eqs. (8) and (9). At $I, U_{A}^{\prime}=\mu p_{s}$, but $U_{A}^{\prime \prime}>0$ which implies that $I$ is a minimum. At point $H$, $U_{A}^{\prime}>\mu p_{s}$ evaluated from the left, but $U_{A}^{\prime}<\mu p_{s}$ evaluated from the right. Therefore, $s_{\mathrm{h}}$ is a maximum solution. Similarly, at point $J$ with consumption level zero, $U_{A}^{\prime}<\mu p_{s}$ which means that the individual would have no incentive to raise consumption marginally from this point. Thus it too is a maximum.

The global maximum will be either at point $J$ or $H$ and will depend on the curvature of the functions. In Fig. 5 we present an indifference curve and budget constraint to depict the individual's optimization problem. The indifference curves rise, then decline, as cigarette consumption rises from zero because additional consumption of cigarettes raises utility at an increasing rate before the habitual level is reached. Beyond the habitual level additional cigarette consumption is a net 'bad' rather than a 'good', therefore the indifference curves slope upwards. The solid line $Y_{1}$ in Fig. 5 is an indifference curve for an individual who has reached an age such as $A 2$ in Fig. 4. (Note: the dashed-line indifference curves $Y_{2}$ and $Y_{3}$ do not yet apply).

With relative prices given by the slope of the budget line, there is a global optimum at point $C$. However, there will be at least two other local optima, at

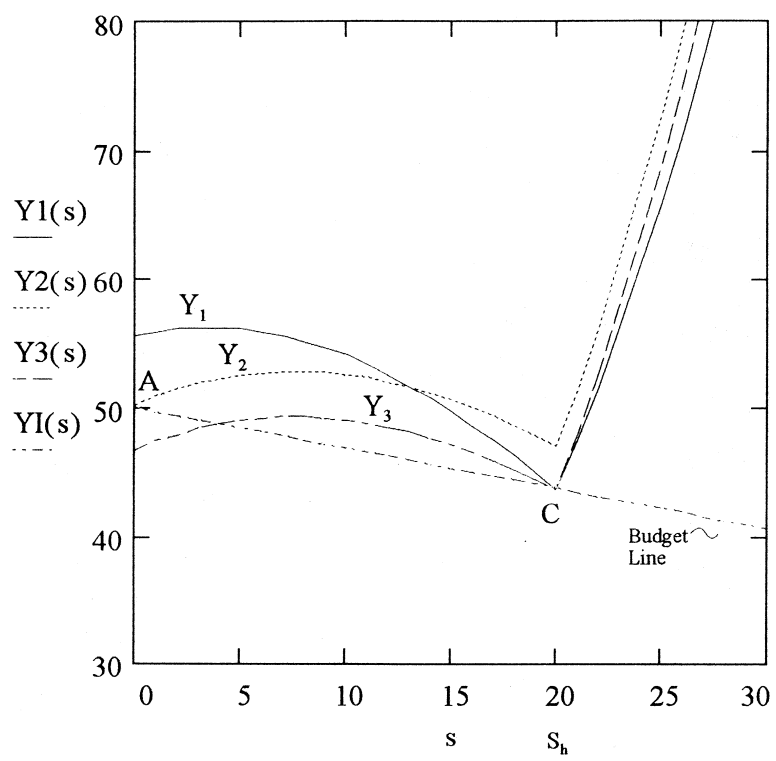

Fig. 5 . 
which the first order conditions are fulfilled. One will be a corner solution on the vertical axis, where a lower indifference curve (not shown) hits the budget line at point $A .{ }^{19}$ A second optimum, in this case a minimum, would exist where a lower indifference curve (also not shown) is tangent to the budget line somewhere between points $A$ and $C$. A smoker who faces the indifference curve $Y_{1}$ would maximize utility by continuing to smoke at the habitual level $s_{\mathrm{h}}$.

Next, suppose that a consumption shock occurs. Perhaps a smoker's obligations force him to spend a day at a location where smoking is prohibited. This would force our smoker to point $A$. At the end of the day, once smoking is allowed again, the smoker would have no incentive to marginally raise consumption. ${ }^{20}$

However, although two local maxima arise (at points $C$ and $A$ ) the smoker with full information about his utility at all consumption levels knows that by smoking at level $s_{\mathrm{h}}$ rather than zero, he can avoid the adjustment cost and realize greater overall utility. Thus, even a consumption shock should only cause temporary movement away from $C$ and the smoker would immediately revert back to his known global maximum at consumption level $s_{\mathrm{h}}$.

As the smoker gets older, cold turkey quitting can arise in this model even without an exogenous shock. As future losses rise with age, the indifference curves will rotate. The curves $Y_{2}$ and $Y_{3}$ represent two different levels of utility for an older individual. It is easily seen that the global optimum has shifted to a consumption level of zero. Indeed, at some moment between the smoker's age when $Y_{1}$ holds and his age when $Y_{2}$ holds, the smoker will become indifferent between smoking zero or smoking at the habitual level. In all periods beyond that time, a zero consumption level will be the optimum. Thus a smoker with full information will quit smoking cold-turkey once that particular age is reached. Intuitively, cold-turkey quitting occurs when the expected negative health consequences of continuing to smoke (which continually rise over time) minus the benefits of smoking, become more painful than the discomforts that will arise with cold-turkey quitting. It is worth noting that the model's prediction that quitting rises with age is consistent with empirical data (see Douglas, 1998).

\subsection{Case 3}

In case three we assume the adjustment costs change at a decreasing rate for consumption levels near zero but an increasing rate for consumption levels near

\footnotetext{
${ }^{19}$ The lower indifference curve would have the same shape as $Y_{1}$ but is shifted down.

${ }^{20}$ This scenario is similar to Becker-Murphy's account of cold-turkey quitting in a dynamic context. In their account, it takes a consumption shock to force consumption to the alternative maximum at zero. In their model, if no shock occurs, no cold-turkey quitting will occur. In their account, this exogenous-shock-based cold-turkey quitting is more likely in the case of a relatively strong addiction. Below we generate a similar result about cold turkey quitting being more likely when there is a strong addiction, but our cold-turkey quitting is endogenous.
} 
the habitual level. This function is shown as $C_{A}$ in Fig. 6. In this case, small smoking reductions are relatively painless, but the costs rise rapidly with additional reductions. For additional cut-backs near zero, however, quitting costs rise slowly. Assume that at age $A 1$ the smoker's overall utility effects are given by the function $U_{A 1}$. The optimum occurs at point $H$ with consumption level $s_{\mathrm{h}}$. As one grows older the utility function shifts down (as in the previous cases) while the slope of $U_{A}$ falls at all $s$. Eventually the smoker will face the utility curve $U_{A 2}$. With this function the optimum shifts to point $I$ and consumption is reduced from the original level $s_{\mathrm{h}}$.

Eventually aging will shift the utility function to $U_{A 3}$. As in case 2 above, the function now has two maxima at $J$ and $L$ and one minimum at point $K$. Upon reaching this situation the global optimum will be at $J$ but as time progresses that optimum will shift discretely to zero.

In this case an individual's smoking pattern would consist of three stages. In the initial stage the smoker would consume at a fixed positive level. Eventually the smoker will enter a second stage in which a gradual reduction in average consumption ensues. Finally the smoker would quit smoking cold-turkey from some positive level.

This pattern is indicative of smokers who attempt to quit numerous times before they are successful. As documented above, smokers often attempt to quit, only to experience a relapse within a week or two. Smokers trying to quit will sometimes stop buying cigarettes but will continue to bum cigarettes from fellow smokers. In

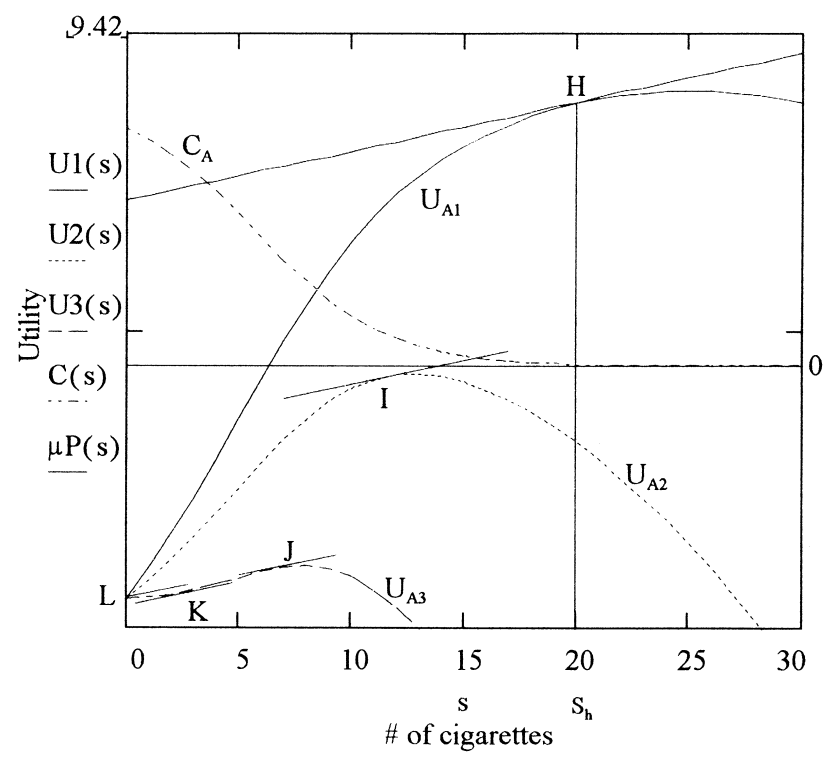

Fig. 6 . 
this way average consumption is reduced, even though periods of smoking at the habitual level may continue. Sometimes smokers may continue such attempts for months or years before cold-turkey quitting is finally successful. Perhaps the effect of these periodic attempts to quit is merely the gradual reduction in the average daily consumption of cigarettes. This may occur because the adjustment cost of small reductions in cigarette smoking may not be very significant. Once average consumption reductions reach the level where the cost of quitting rises rapidly, cold-turkey quitting can become optimal as long as the future health consequences weigh heavily enough.

\section{A 'more realistic' set of assumptions}

The modeling above used the idea that each cigarette reduces one's life by a fixed number of minutes. While this assumption is easy to understand, and facilitates a more intuitive diagrammatic exposition of a complex modeling process, it may not be the best way to assess the future health consequences of smoking. In particular, some deaths attributable to smoking occur when an individual is relatively young, such as when a smoker dies of a smoking-induced heart attack in his thirties.

This idea that smoking might affect the probability of death at various ages can be incorporated into the model by assuming that smoking raises the probability of dying at subsequent ages. In Appendix A we modify our model to include this probabilistic assumption. Specifically, we present a formula with numerical coefficients that closely approximates the probabilities found in the 1992 Life Tables for the U.S. population. Our modeling then assumes that smoking affects these probabilities that one will die in all subsequent periods of one's life; that is, that a stock of past cigarette smoking raises the rate of growth of the death rate.

Appendix A shows that use of this assumption preserves the key feature of the previous model, namely that the expected losses from smoking rise with age, albeit with two important modifications. First, when an individual approaches the end of his life-at approximately age 70 with our numerical specification-expected future losses from smoking decline with age. This occurs because at older ages the natural chances of dying (for all people) become so high that the marginal effect of smoking becomes less consequential. Second, very early in life (around age 15) there may be a decrease in future losses for a period of years-up to age 25 using our numbers-after which future losses increase. This effect occurs because increases in the smoking stock raise the probability of dying at a decreasing rate and because the probability of dying soon is very low. This implies that a young smoker is less likely to quit as he becomes older, at least for some period of time.

These modified results from using a more realistic and complex numerical assumption about how smoking affects probabilities of dying suggest the impor- 
tance of incorporating into the model better information about how smokers actually perceive the health effects of smoking.

\section{Demand responsiveness to shocks}

One area of controversy within the addiction literature involves the responsiveness of demand for cigarettes to changes in price or other exogenous shocks. For some who consider addiction an irrational behavior, policies such as higher consumption taxes or greater dissemination of health information will have little to no effect upon the demand for cigarettes. Empirical studies by Townsend (1987), Becker et al. (1991, 1994) and Chaloupka (1991), among others, show that cigarette consumption is responsive to price changes. The model presented here provides motivation to explain both of these results.

As demonstrated above, an individual who has smoked long enough to develop quitting costs will face a kink in her utility function which we define as her habitual consumption level. For such individuals, small price changes or small exogenous shocks such as the dissemination of health information, are unlikely to affect their level of usage. As such their demand is unresponsive to price changes. 21

However, some of the empirical studies demonstrating demand responsiveness use aggregate consumption and price data. At any moment in time there will be individuals at many different stages of smoking consumption. Some are at the stage of just beginning to smoke. Some have just begun and have not yet seen their quitting costs rise significantly. Some are longtime smokers who have no desire to quit. Some are longtime smokers who wish they could quit, but cannot. Finally, some are longtime smokers who are already in the process of gradual quitting or are about to quit cold-turkey. Indeed, some interesting work by psychologists studying the process of smoking cessation uses what is called the 'stages of change' model, which places smokers in five different stage categories depending on the degree to which they are contemplating or taking actions to try to stop smoking (see, for example, Prochaska et al., 1992, and Prochaska and DiClemente, 1983). ${ }^{22}$

\footnotetext{
${ }^{21}$ Such inelasticity may apply to some nonaddictive goods as well. For example, someone might habitually drink a glass of orange juice every morning despite price fluctuations.

${ }^{22}$ Prochaska et al. (1992) observe that "The vast majority of addicted people are not in the action stage. Aggregating across studies and populations...10\%-15\% of smokers are prepared for action, $30 \%-40 \%$ are in the contemplation stage, and $50 \%-60 \%$ are in the precontemplation stage'. (p. 1105). The precontemplation stage is one where the smoker is not thinking about ('contemplating') quitting. In the contemplation stage "people are aware that a problem exists and are seriously thinking about overcoming it but have not yet made a commitment to take action'”. (p. 1103).
} 
When prices increase or when a burst of new health information is disseminated, some of those who are about to start, may not. Some of those who had recently begun to smoke may also quit. Those longtime smokers who were soon to quit, may quit a bit sooner. Thus in the aggregate, our model would predict some responsiveness of demand to changes in price and other exogenous shocks, even though for some individuals there would be no response at all.

Also, since younger individuals will more likely be those who are soon to begin smoking or who have not developed significant quitting costs, the model would predict greater demand responsiveness to price changes among teenagers relative to the rest of the population. This is consistent with the empirical results of Lewit and Coate (1982), Chaloupka and Grossman (1996), and Chaloupka and Wechsler (1997).

\section{Applications of the model}

Because this model explicitly incorporates quitting costs, it can explain the existence of behavior modification treatments such as Smokenders or nicorette gum. These treatments are chosen because it is hoped they will make quitting easier, that is to reduce quitting costs. Furthermore, these treatments may be experience-goods. If so, then a decision to try, say, nicorette gum, would initially be based on the smokers expectation of its likely effects. If the actual effects turn out less efficacious than expected, a smoker may quickly suffer a relapse. If there are many methods to aid quitting and each one has a different expected cost, then a repetitive cycle of quitting followed by relapse may ensue as a smoker learns the true costs of each method. As we noted above, Prochaska et al. (1992) cite evidence that successful quitters typically relapse several times before achieving success. The repetitive cycle could also arise even with only one available treatment if smokers attribute previous failures to quit as being determined mostly by other factors. For example, the passing of a stressful period in one's life may induce another quitting attempt using a previously unsuccessful method if it is believed that the stress rather than the treatment was the primary cause of the failure.

The model can also be applied to the recently debated issue concerning the effect of advertising on teenagers. Advertising can be incorporated into the model as an upward shift of an individual's current benefit function. Certainly, if smoking seemed more glamorous, one would get more current utility from smoking. Consider the effects of advertising on two non-smokers; a teenager and a middle-ager. The model would suggest that any shift to the teenager's benefit function is more likely to induce smoking compared to an equal shift in the middle-ager's benefit function. To induce an older individual to begin smoking the advertisement would need to shift current benefits to overcome relatively larger future losses. Since the teenager is likely to have much lower perceived future 
losses, the benefit shift would not need to be as large to induce smoking. This suggests that even if advertising equally affected the perception of benefits for all age groups, younger individuals will still be more likely to respond to advertising by beginning to smoke.

\section{Conclusion}

This paper uses a model in which individuals act in their own self-interest to explain many seemingly irrational choices by cigarette smokers. Our model is similar to the Becker-Murphy rational addiction model in that past consumption of cigarettes influences current choices. However, we reinterpret or re-characterize a number of assumptions. Among these changes are the explicit modeling of quitting costs and incorporation of the fact that the effects of smoking are concentrated later in one's life. These changes allow us to offer more intuitive explanations for the behavior of smokers.

For example, the model can clearly show why smokers may be unhappy about their decision to smoke, express a sincere desire to quit, yet find themselves unable to do so. The model also shows how a smoker may experience a change of perspective as he grows older sufficient to induce cold-turkey quitting. Our model does not require an exogenous shock or a stressful event to generate this outcome, although the model does not preclude the possibility that a shock could induce cold-turkey quitting. As in Becker-Murphy we show that cold-turkey quitting is a more likely outcome for a 'strong' addiction. In our case we define a strong addiction when quitting costs rise rapidly for small reductions in consumption. If the addiction is weak, so that quitting costs rise slowly for small reductions in consumption, then the smoker will quit gradually; another result not captured with the Becker-Murphy model. The model also shows that small price changes may have no effect upon a smoker's consumption level although it would likely move forward an eventual quitting date. Nevertheless because at any time there are many smokers at different stages of consumption, the model is consistent with aggregate empirical results demonstrating demand responsiveness to changes in prices. Finally the model is extended to provide a simple explanation for smokers' use of 'quit-smoking' treatments like Smokenders and nicorette gum, and to explain why teenagers may empirically seem more susceptible to advertising.

One important issue among researchers of addiction is the appropriate role of government in regulating the production and sale of dangerous commodities like cigarettes. Since our model explains addiction by assuming that individual's choices are made in one's own best interest, we could argue that the government could not intervene without undermining the individual's right to choose something which primarily affects no one but himself. However, our model does suggest that individuals may lead themselves into a consumption 'trap' from which they cannot free themselves. In this case potential smokers, or parents of 
potential smokers, may accept government intervention to prevent people from setting their own trap and to help people free themselves once they've become trapped. The model suggests that higher consumption taxes could prevent more young smokers from starting and encourage current smokers to quit sooner. However, for many smokers, higher taxes would not induce quitting. These people would then suffer the burden of higher taxes as well as the harmful effects of smoking. Of course, one could argue that the higher taxes merely pay for the higher social costs caused by smokers. However, recent studies disagree about whether smoking raises social costs. ${ }^{23}$ If smoking does not raise costs, then taxes may merely inflict additional punishment upon non-quitters.

Finally although our model is specifically designed to explain the behavior of cigarette smokers, it could readily be adapted to other types of addictive behavior like alcoholism, other drug dependencies and even positive addictions such as music appreciation. Analysis of drug use, however, would require a change in the timing of consumption costs and benefits. For example, although regular excessive alcohol use can cause liver failure and reduce one's life expectancy, it may also cause detrimental utility effects in the present by severing family relationships and perhaps affecting current employment opportunities. Different time patterns of costs and benefits are also likely for other dependencies. These applications remain potential topics for future research.

\section{Acknowledgements}

We would like to thank Bryan Boulier, David Goldbaum, Chris Snyder, participants in seminars at American University and the University of Maryland, Baltimore County, several referees and the editor for helpful comments.

\section{Appendix A. Alternative modeling approach for future losses}

Although the assumption that every cigarette reduces one's life by seven minutes is easy to understand, it may not be the most accurate way to assess the future health consequences of smoking. Not every smoker dies earlier than a comparable non-smoker. Some lifetime smokers live beyond the age of 100. Some deaths attributed to smoking occur when an individual is relatively young, as when a smoker dies of a heart attack in his thirties or forties. Thus, a more accurate way to assess the health effects of smoking is to assume that smoking raises the

\footnotetext{
${ }^{23}$ A recent study in the New England Journal of Medicine (Barendregt et al., 1997) suggests that complete smoking cessation would raise net health care costs. Conflicting evidence can be found in Hodgson (1992). See also, Manning et al. (1991).
} 
Table 1

The probability that a 20 -year-old will live to a later age $A$

\begin{tabular}{lll}
\hline Age & 1992 US Life Tables & $\operatorname{prl}(20, t, 0)$ \\
\hline 20 & 1.000 & 1.000 \\
30 & 0.989 & 0.989 \\
40 & 0.971 & 0.971 \\
50 & 0.941 & 0.938 \\
60 & 0.874 & 0.873 \\
70 & 0.733 & 0.744 \\
80 & 0.493 & 0.497 \\
\hline
\end{tabular}

probability of dying in subsequent years above the probability that already exists for non-smokers. In this way smoking continues to affect ones expected lifespan, but it is no longer assumed that the effects are expected only at the end of one's life.

In this appendix we present this alternative method to assess the future health consequences of smoking. First we will present a formula which closely approximates the probability that an individual of age $A$ will die in any subsequent year. The formula approximates the probabilities found in the 1992 US Life Tables for the entire US population (Vital Statistics of the United States, 1992). Using these probabilities as a base, we will assume that smoking raises the probability that one will die in all subsequent periods of one's life, that is, that a stock of past cigarette consumption raises the rate of growth of the death rate. We will then show that the key feature of the previous model, namely that the expected losses from smoking rise with age, continues to hold in this version, albeit with some qualifications.

\section{A.1. The model}

As before, consider an individual who is currently $A$ years old. Let the probability that an individual at age $A$ will live to age $t$ be defined as

$$
\operatorname{prl}\left(A, t, S_{A}\right)=e-\int_{A}^{t} \mu\left(t, S_{A}\right) \mathrm{d} t
$$

where $\mu\left(t, S_{A}\right)$ is the death rate given by,

$$
\mu\left(t, S_{A}\right)=k\left(S_{A}\right) e^{\left(-7.643726+0.020798 t+0.0005033 t^{2}\right)} .
$$

As before we assume $S_{A}$ is the total accumulated stock of cigarette consumption for the individual at age $A . k\left(S_{A}\right)$ is a function we will use to make the death rate dependent on the level of past cigarette consumption. ${ }^{24}$

To demonstrate that this functional form represents a close approximation to actual probabilities we present in Table 1 the probability that a 20 -year-old will live to subsequent ages as derived from 1992 US Life Tables for the entire

\footnotetext{
${ }^{24}$ Our colleague Bryan Boulier constructed this formula to fit the existing mortality data.
} 
Table 2

Simulated increase in the death rate relative to a non-smoker: $k\left(S_{A}\right)$

\begin{tabular}{llll}
\hline Years smoked & 10 cigarettes /day & 20 cigarettes /day & 40 cigarettes / day \\
\hline 1 & 1.103 & 1.198 & 1.363 \\
10 & 1.508 & 1.835 & 2.089 \\
20 & 1.605 & 1.958 & 2.151 \\
\hline
\end{tabular}

population and compare this with the probabilities derived using the above formula, i.e. $\operatorname{prl}(20, t, 0)$. We will assume that the individual is a non-smoker so we set $S_{A}$ to zero which in turn will imply that $k=1$.

Let $s_{t}$ represent the number of cigarettes consumed in period $t$. Assume that $\mathrm{sa}_{t}$ represents the annual rate of cigarette consumption at age $t$. We will assume that the smoking stock depreciates at a rate of $\delta=0.10$ per year. This would imply that a longtime smoker's probability of dying would revert to that of a non-smoker after approximately $10 \mathrm{yr}$ of continued abstinence. The smoking stock at age $A$ can now be written as $S_{A}=\int_{t=0}^{A}(1-\delta)^{\mathrm{A}-\mathrm{t}} \mathrm{sa}_{\mathrm{t}} \mathrm{d} t$.

We choose a functional form for $k\left(S_{A}\right)$ such that: (1) $k(0)=1$, which means that the death rate is the same as the average population for a non-smoker; (2) $k^{\prime}\left(S_{A}\right)>0$, which implies that the death rate rises as the stock of past consumption rises; (3) $k^{\prime \prime}\left(S_{A}\right)<0$ which means that the death rate rises at a decreasing rate with increases in the stock; and (4) $\lim _{S_{A} \rightarrow \infty} k\left(S_{A}\right)=\alpha$, which implies that the death rate approaches an upper bound, $\alpha$, as $S_{A}$ becomes very large. The following function satisfies the above conditions.

$$
k\left(S_{A}\right)=\alpha-(\alpha-1) e^{\left(-\gamma S_{A}\right)} .
$$

Note that since $k(0)=1$, from Eq. (A2), $k\left(S_{A}\right)=\left(\mu\left(t, S_{A}\right)\right) /(\mu(t, 0))$. That is, $k\left(S_{A}\right)$ represents the degree to which a smoker's death rate exceeds a non-smoker's death rate. In the simulations we assume, $\alpha=2.2$ and $\gamma=0.00001$.

In Table 2 below we depict the simulated increase in the death rates, given by $k\left(S_{A}\right)$, relative to a non-smoker for three different daily consumption rates, $(10,20$ and 40 cigarettes per day), over three different time horizons, ( $1 \mathrm{yr}, 10 \mathrm{yr}$ and 20 yr). ${ }^{25}$

The present value of a smoker's expected future utility stream $(V)$ at age $A$ can now be written as,

$$
V\left(A, S_{A}\right)=\int_{t=A}^{100} e^{-r(t-A)} \operatorname{prl}\left(A, t, S_{A}\right) W_{t} \mathrm{~d} t
$$

where $r$ is the fixed discount rate, $e^{-r(t-A)}$ is the discount factor at time $t$, and $W_{t}$ is the individual's expected utility in period $t$.

\footnotetext{
${ }^{25}$ Note that these increases in the death rates are similar to those found in previous studies of mortality. See especially Preston (1970) (p. 53).
} 
In order to evaluate the present discounted value of future utility an individual must make some assumption about the value of $W_{t}$ at all future periods of their life. This problem is complicated by the fact that smoking at any point in one's life is assumed to raise the probability of dying in future periods which, in turn, would reduce expected utility in those periods. Although a person might readily determine how past and current smoking would affect future probabilities, it is also true that future smoking will affect future probabilities. Thus in order for the model to be completely specified, the individual smoker would have to determine today, their expected future smoking behavior in order to determine their expected future utility. For simplicity we will assume that the individual is, in a sense, boundedly rational with respect to future smoking effects on future utility. As such we will assume that the individual has an exogenous expectation of a fixed expected utility level, $W_{t}$, at each future period, independent of today's decision. ${ }^{26}$ Furthermore, even though one's expected utility might vary over one's life-cycle due to income variations, in the simulations we shall assume that expected utility is constant across periods.

For an individual at age $A$, the present value of the expected future losses resulting from this period's smoking is given as,

$$
L\left(A, S_{A}, s\right)=V\left(A, S_{A}\right)-V\left(A, S_{A}+s\right)
$$

where $s$ represents smoking in the present period.

Although analytical solutions are difficult to derive, our simulations indicate that $\left(\partial L\left(A, S_{A}, s\right)\right) /(\partial s)>0$. Future losses will rise as current period smoking, $s$, rises, given a fixed age and cigarette stock, because smoking increases the rate of growth of the death rate. Thus the probability of dying is increased for all future periods which means discounted expected future utility must fall.

However, as a smoker becomes older (i.e. $A$ rises) there are two changing variables that will affect his expected future losses, age itself and the growing cigarette stock. An increase in the cigarette stock, for a given age and given level of daily smoking, reduces one's expected future losses from smoking, (i.e. ( $\partial L(A$, $\left.\left.\left.S_{A}, s\right)\right) /\left(\partial S_{A}\right)<0\right)$. This is because the death rate rises at a decreasing rate with additions to the stock. Thus 20 cigarettes smoked by a 20 -year-old who has smoked for one year will raise his death rate by more than 20 cigarettes smoked by a 20 -year-old who has smoked for five years.

\footnotetext{
${ }^{26}$ Essentially we are only allowing the agent to take account of first order effects on future utility through the effect of current smoking on future probabilities of dying. In contrast a fully rational agent, taking all intertemporal effects into account, would have to determine a lifetime consumption plan today. This is because today's smoking would likely affect future utilities as well as future probabilities. The effect on future utilities would affect future smoking decisions which would affect the path of lifetime utilities. Our assumption that the agent is boundedly rational implies that he does not account for all of these interactions simultaneously.
} 
On the other hand, an increase in age for a given stock and level of daily consumption, will raise one's expected future losses from smoking, at least at younger ages, (i.e. $\left.\left(\partial L\left(A, S_{A}, s\right)\right) /(\partial A)>0\right)$. This is because as one grows older the death rate rises naturally for both smokers and non-smokers. Thus the increase in the death rate caused by smoking raises the death rate more rapidly because the base death rate is increasing with age. When age approaches the end of life, however, (approximately 70 years old in our simulation) then expected future losses from smoking decline with age. This occurs because the natural increase in the death rate begins to exceed the increase caused by smoking.

Using the earlier model specified in the text, where smoking reduces one's expected lifespan, we show that as a smoker becomes older the expected future losses from smoking increase. This effect drives the result in the text that as a smoker becomes older he is more likely to quit. In contrast, in this appendix model, as a smoker becomes older there are two offsetting effects: an age effect and a stock effect. An increase in age for a given stock raises his expected future losses. However, the increase in the stock for a given age reduces expected future losses. The net effect is simulated using the parameters specified above and the results are shown below in Fig. 7. What we show is a plot of the present value of the expected future losses from smoking 0 to 30 cigarettes today for an individual of age $15,25,45$, and 65 respectively. This corresponds to a plot of the functions

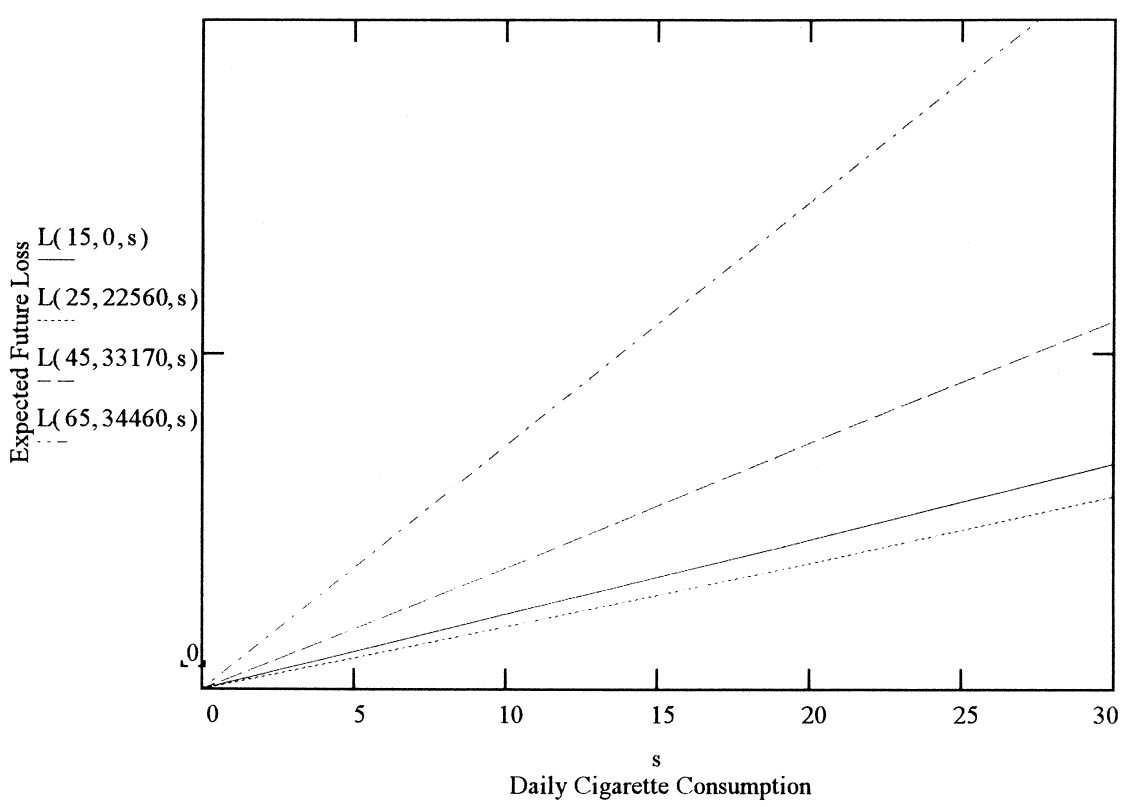

Fig. 7. 
$L(15,0, s), L(25,22560, s), L(45,33170, s)$ and $L(65,34460, s)$. The stock at each age is calculated under the assumption that the individual had been a ten cigarette per day smoker since the age of 15 and that the stock depreciates at a ten percent annual rate. Of course, this implies that the stock for a 15-year-old is zero. The figure shows that expected future losses initially fall as a ten per day smoker ages from 15 to $25 \mathrm{yr}$. Based on the analysis in the text, this would suggest that this 15-year-old would be unlikely to quit smoking by the age of 25 unless some shock occurs which affects his other perceived benefits and costs. However, as the individual continues to smoke and grow older his expected future losses will rise. This is similar to the result obtained in the model in the text. By the age of 45, expected losses exceed those perceived as a 15-year-old. These losses continue to rise until age 65 . Eventually these losses would begin to shift down again once the individual nears age 80 .

It is interesting to note that these effects differ for a heavier smoker. In Fig. 8 below we present the same future loss functions at the same ages, but assume that the individual begins a 40 cigarette per day habit at the age of 15 . As before, the stock at each age is calculated under the assumption that the individual had been a 40 cigarette per day smoker since the age of 15 and that the stock depreciates at a ten percent annual rate.

Notice that although the pattern of changes is the same as before, i.e. losses fall then rise with cigarette consumption over the individual's life, in this case the

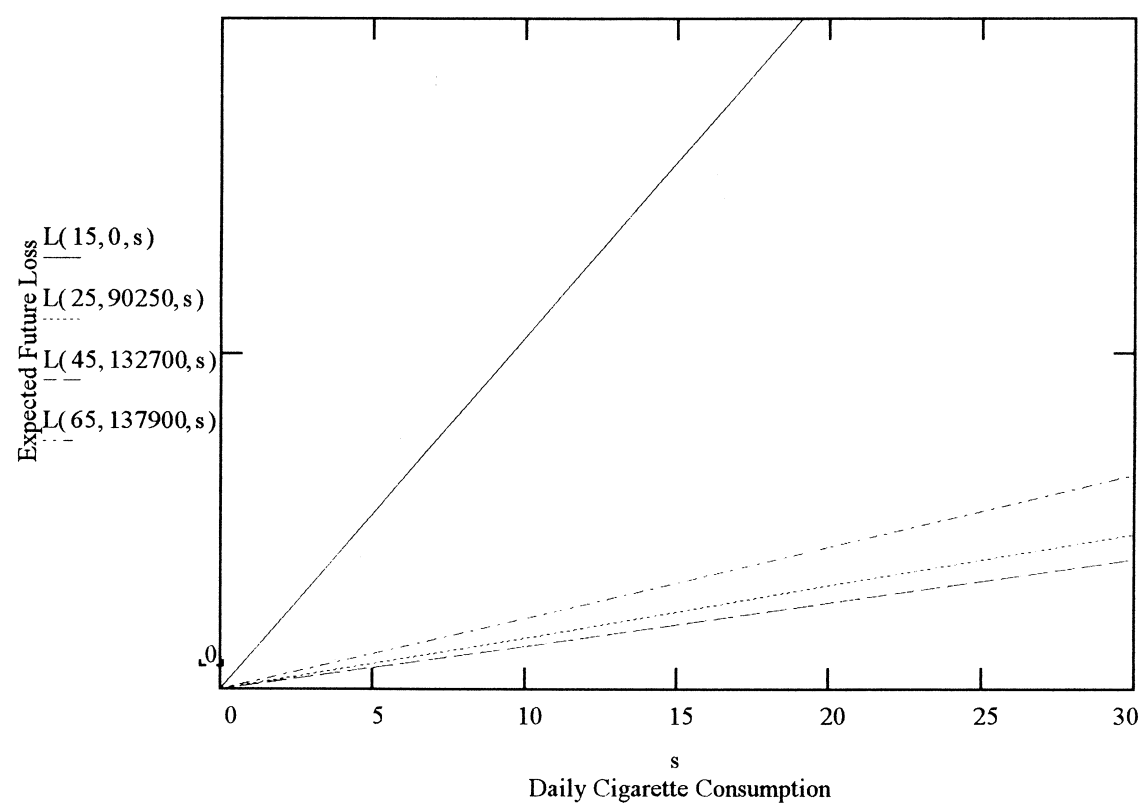

Fig. 8 . 
expected losses do not rise up above the perceived losses at age 15. This would suggest, based on the analysis of quitting in the text, that a heavy smoker would be much less likely than a light smoker to quit as he becomes older. This is because the reduction of losses due to stock growth greatly exceeds the addition to losses as a result of age.

It is interesting to note that using this model a heavy smoker is less likely to quit compared to a lighter smoker as he becomes older, and yet, this is not due to an assumption that heavy smoking raises addictiveness. If addictiveness were higher for heavier smokers then the quitting costs would be much higher. In this model version a heavy smoker is less likely to quit because the expected future losses of smoking for an older individual do not overtake the perceived future losses at age 15 .

\section{References}

Barendregt, J.J., Bonneux, L., van der Maas, P.J., 1997. The health care costs of smoking. New England Journal of Medicine 337, 1052-1057.

Becker, G.S., Murphy, K.M., 1988. A Theory of rational addiction. Journal of Political Economy 96, $675-700$.

Becker, G.S., Grossman, M., Murphy, K.M., 1991. Rational addiction and the effect of price on consumption. American Economic Review 81, 237-241.

Becker, G.S., Grossman, M., Murphy, K.M., 1994. An empirical analysis of cigarette addiction. American Economic Review 84, 396-418.

Chaloupka, F., 1991. Rational addictive behavior and cigarette smoking. Journal of Political Economy 99, 722-742.

Chaloupka, F., Grossman, M., 1996. Price, tobacco control policies, and youth smoking. Working Paper No. 5740. National Bureau of Economic Research.

Chaloupka, F., Wechsler, H., 1997. Price, tobacco control policies, and smoking among young adults. Journal of Health Economics 16, 359-373.

Cross, J.G., Guyer, M.J., 1980. Social Traps. University of Michigan Press, Ann Arbor.

Douglas, S., 1998. The duration of the smoking habit. Economic Inquiry 36, 49-64.

Hamermesh, D.S., Hamermesh, F.W., 1983. Does perception of life expectancy reflect health knowledge?. American Journal of Public Health 73, 911-914.

Harris, J., 1993. Deadly Choices: Coping with Health Risks in Everyday Life. Basic Books, New York.

Herrnstein, R.J., Prelec, D., 1992. A theory of addiction. In: Lowenstein, G., Elster, J. (Eds.), Choice Over Time. Russell Sage Foundation, New York.

Hodgson, T.A., 1992. Cigarette smoking and lifetime medical expenditures. Milbank Quarterly 70, $81-125$

Lewit, E.M., Coate, D., 1982. The potential for using excise taxes to reduce smoking. Journal of Health Economics 1, 121-145.

Manning, W.G. et al., 1991. The Cost of Poor Health Habits. Harvard Univ. Press, Cambridge, MA.

Orphanides, A., Zervos, D., 1995. Rational addiction with learning and regret. Journal of Political Economy 103, 739-758.

Peele, S. (Ed.), 1988. Visions of Addiction. Lexington Books, Lexington, MA.

Pollak, R.A., 1970. Habit formation and dynamic demand functions. Journal of Political Economy 78, $754-763$.

Preston, S.H., 1970. Older male mortality and cigarette smoking. A demographic analysis. Population Monograph Series, No. 7. Institute of International Studies, Berkeley, CA. 
Prochaska, J., DiClemente, C., 1983. Stages and processes of self-change of smoking: toward an integrative model of change. Journal of Consulting and Clinical Psychology 51, 390-395.

Prochaska, J., DiClemente, C., Norcross, J., 1992. In search of how people change: applications to addictive behaviors. American Psychologist 47, 1102-1114.

Schelling, T., 1984. Self-command in practice, in policy, and in a theory of rational choice. American Economic Review 74, 1-11.

Schoenbaum, M., 1997. Do smokers understand the mortality effects of smoking? Evidence from the health and retirement survey. American Journal of Public Health 87, 755-759.

Simon, H., 1978. Rationality as process and as product of thought. American Economic Review 68, $1-16$.

Stigler, G., Becker, G.S., 1977. De gustibus non est disputandum. American Economic Review 67, $76-90$.

Thaler, R., Shefrin, H., 1981. An economic theory of self-control. Journal of Political Economy 89, 392-410.

Thombs, D., 1994. Introduction to Addictive Behaviors. Guilford Press, New York.

Townsend, J.L., 1987. Cigarette tax, economic welfare, and social class patterns of smoking. Applied Economics 19, 355-365.

Viscusi, W.K., 1992, Smoking: Making the Risky Decision. Oxford Univ. Press.

Vital Statistics of the United States, 1992. Life Tables, Vol. 2, Section 6, April 1996, Pub. No. (PHS) 96-1104. U.S. Department of Health and Human Services, Hyattsville, MD.

Winston, G.C., 1980. Addiction and backsliding: a theory of compulsive consumption. Journal of Economic Behavior and Organization 1, 295-324.

Yaari, M.E., 1978. Endogenous changes in taste: a philosophical discussion. In: Gottinger, H., Leinfellner, W. (Eds.), Decision Theory and Social Ethics. Reidell, Dortrecht, pp. 59-98. 